\title{
22 SUPPLEMENTS CONTAINING BANNED SUBSTANCES
}

Rymantas Kazlauskas Chemical and Biological Metrology Branch, National Measurement Institute, New South Wales, Australia

10.1136/bjsm.2010.078725.22

Over the past years, NMI has been monitoring and determining compounds contained in so called 'supplements', which are or can be classified as banned within the definitions of the WADA Prohibited List. The items studied have been chosen for investigation because the advertised content declarations show that major ingredients may fall into this banned category. It is clear that many of these fall into a designer steroid category, but others are already classified as banned. Issues relating to labelling, purity of contents identification of materials will be discussed. New trends in this 'supplement' market as well as trends in the sale of substances on the internet show a very disturbing pattern and the health of the public purchasing and using these products may be at risk. 